\title{
Contraception Method Preferences Among Women in Two Ghanaian Cities
}

\author{
Sarah D Rominski ${ }^{*}$, Abubakar Manu ${ }^{2}$, Ernest Maya ${ }^{2}$, Emmanuel Morhe ${ }^{3}$ and Vanessa K Dalton ${ }^{4}$ \\ ${ }^{1}$ Department of Obstetrics and Gynecology, University of Michigan, USA \\ ${ }^{2}$ Department of Population, Family and Reproductive Health, University of Ghana School of Public Health, Ghana \\ ${ }^{3}$ Department of Obstetrics and Gynecology, University of Health and Allied Sciences Ho, Ghana \\ ${ }^{4}$ Department of Obstetrics and Gynecology, University of Michigan Medical School, USA
}

Submission: July 12, 2018; Published: September 18, 2018

*Corresponding author: Sarah D Rominski, Research Assistant Professor, Program on Women's Healthcare Effectiveness Research, Department of Obstetrics and Gynecology, University of Michigan, USA; Email: sarahrom@med.umich.edu

\begin{abstract}
Background: While availability of women's preferred methods is an important indicator of quality of family planning services, the preferences Ghanaian women hold around contraceptive methods are largely unknown.

Methods: We conducted a facility-based survey in five family planning clinics in Ghana's two largest cities. Women were interviewed before and after their family planning counseling session. In the pre-visit interview, women were asked both the method they most preferred, as well as method characteristics which appealed to them. In the post-visit interview, they were asked which method they were leaving with, if they received the method they most preferred, and how satisfied they were to be leaving with their method. A series of bivariate logistic regressions were performed to assess factors associated with certain method preference and adoption.
\end{abstract}

Results: A total of 337 women were interviewed and able to be linked pre- and post-visit. Most of the participants (54.1\%, $\mathrm{n}=482)$ stated a preference for a long acting reversible contraceptive (LARC) method (either an implant (40.7\%, n=137) or an IUD (13.4\%, $n=45)$ ), while a sizable minority of the participants stated a preference for an injectable $(32.3 \%, n=109)$. Only $5 \%(n=17)$ participants said they did not know which method they preferred. In bivariate logistic regression analysis, older and married women and those with higher education were more likely to want the IUD, while unmarried and younger women preferred the injection. Women who wanted a method that would protect them for multiple years showed preference for the IUD and the implant, while women who wanted pregnancy protection for a few months and those who did not want a method which requires a visit to the clinic to stop using preferred the injection.

Conclusion: Our study participants were most likely to want, and receive, a LARC method, mainly the implant. These participants have strong preferences, which are generally being met. Further work should investigate whether women who receive their preferred method are more likely to continue using the method than those who do not.

Keywords: Contraception; Ghana; Preferences

Abbreviations: LARC: Long Acting Reversible Contraceptive; ICPD: International Conference on Population and Development; CPR: Contraceptive Prevalence Rate; TFR: Total Fertility Rate

\section{Introduction}

The idea of reproductive rights as being integral to human rights was introduced in 1994 at the International Conference on Population and Development (ICPD) in Cairo. With this shift came an understanding that family planning is one way to help women achieve their human rights as well as the introduction of concepts such as quality of care, voluntary adoption of contraception, and informed choice as measures of success in family planning programming [1]. Prior to this shift, family planning programs were almost singularly focused on reducing fertility as a means of population control, and therefore economic development. There is a new focus on being protective of a woman's right to have the number of children she wants, when she wants them. This shift is apparent in how success is determined. Success of family planning initiatives was once measured almost exclusively by increasing the contraceptive prevalence rate (CPR) and reducing the total fertility rate (TFR) in a given country [1].

In 1990, Judith Bruce first declared choice of methods as an important metric of the quality of family planning services [2]. Since this is hard to measure at the country-level, one proxy for choice availability is method mix, the percent distribution of contraceptive users by method [3]. While there is no ideal method 
mix, nor any gold standard as to what constitutes the "right" mix of methods, and skewed method mix may be due to social trends or cultural beliefs, the dominance of a particular method might also point to method unavailability or provider bias, indicating low quality of care [4]. In a recent analysis as part of the Family Planning 2020 initiative, which aims to add an additional 120 million users of modern contraception in 69 of the world's poorest countries by the year 2020 , it was found that at least $40 \%$ of users use one method in 39 countries, although the most-used method varies by country [5]: pg. 119]. If this skewed method mix is due to program design, provider bias, or commodity availability, the user's rights are not being protected. However, if this skew is reflective of true user preference, then rights have been protected, although some analysts have argued that such situations merit further investigation $[3,5]$.

Use of contraception in Ghana increased dramatically between the 1980s and early 2000s, from 13.0 percent in 1988 to 23.5 percent in 2008 [6], and total fertility subsequently declined. However, since then, use has plateaued and, between the 2008 and 2014 Demographic and Health Surveys, declined slightly to 22.8 percent [7]. Reasons for non-use of contraception, or use of modern versus traditional forms of contraception in Ghana have not been sufficiently investigated. Recently, it has been reported that Ghanaian women's unfavorable attitudes towards contraceptive methods, a key driver in use or non-use, originates from fears regarding the safety of these methods and intolerance of menstrual side effects, rather than from social or moral objections [8].

Beyond protecting women's human rights, ensuring women are being provided with a method of contraception of their preference is one way to increase consistent use of contraception and reduce unwanted pregnancies [9]. However, little is known about the preferences of Ghanaian women in regards to method of contraception. In this study, we sought to describe the preferences, and strength of preferences, among family planning clinic clients at our study sites; describe how clients' preferences changed during their counseling session; describe to what extent women are being provided with the method they prefer; and describe how satisfied clients are with the method with which they are leaving.

\section{Materials and Methods}

\section{Setting and participant recruitment}

This cross-sectional study was conducted in the family planning clinics of two teaching and three urban district hospitals in Kumasi and Accra, Ghana. Data were collected between June 1 and August 31, 2015. All women attending these clinics for family planning counseling and method choice were approached by a member of the study team. The study was presented to the women and if they met the inclusion criteria (being over the age of 18 years, adopting a new method of family planning and able to converse in English, Twi or Ga, the local languages) and those who agreed to participate were taken through a comprehensive verbal consent process. Consenting participants were interviewed both before and after their family planning counseling session. This study used a convenience sample; all women who attended the clinic for family planning during the study period were invited to participate.

\section{Survey instrument}

The survey was developed by the authors, an international study team with experience in family planning in Ghana. Questions were developed based on literature and expert opinion to elucidate method preferences, as well as method-related preferences, such as length of efficacy and potential side effects. The questionnaire was pre-tested among women in the study clinics who met the inclusion criteria as to the target population for clarity and flow before the beginning of data collection. Revisions to the questionnaire were made based on this pilot testing. Questionnaire items included what method of contraception they wanted to adopt and the strength of this preference, previous use of contraceptive methods and reasons for discontinuation, what method characteristics they desired, as well as basic characteristics of the participant, including age, parity, highest level of education, and marital status. After their counseling session, women were asked if they were leaving with a method and if they were, which method and how satisfied they were to be leaving with that method. Participants who adopted a method of contraception were asked if this was the method they wanted. The linked surveys were also compared to assess if women were in fact leaving with the method they had initially indicated was their preference.

\section{Survey administration}

Interviews were conducted both before and after participants' family planning counseling session in a private room near the family planning clinics. Only the woman and the research assistant were in the room where the interview took place. Phone numbers were collected and used to link the pre- and post-visit surveys. All data were collected on a Google tablet computer using Qualtrics software and responses could not be seen once the form was completed. Questionnaires were interview-administered by trained research assistants.

\section{Data analysis}

Data were exported from Qualtrics to excel and then imported into SPSS V.24 (Armonk, NY: IBM Corp) for analysis. Descriptive statistics using frequency tables and cross-tabs were used to explore the data. A series of bivariate logistic regressions were performed to assess factors associated with certain method preference and adoption. Results are presented in Tables 1-4 below.

\section{Ethical review}

All study materials and methods were reviewed and approved by the Ghana Health Service Ethical Review Committee, and the University of Michigan Institutional Review Board.

\section{Results}

Our analytic sample included 337 women, 185 in Kumasi 


\section{Global Journal of Reproductive Medicine}

and 152 in Accra, out of a total of 414 women who completed the first survey, and 411 who completed the second survey. Of those not included, 55 left without a method (primarily due to needing to wait for a pregnancy test $(\mathrm{n}=17)$ and needing to consult with husband ( $(n=5))$, and 22 we were missing one or another of the surveys or could not be matched. Thus, our analytical sample was the 337 who had complete records and were leaving their counseling session with a method of contraception. Participants were generally well distributed across socio-demographic variables; the sample had a mean age of 29.6 years (s.d. 6.7), ranging $18-51$ and $248(60.2 \%)$ were married.

Almost half of the participants $(47.3 \%, n=159)$ had used a method of contraception previously, with the injectable being the most frequently previously used method. Most of the participants $(54.1 \%, \mathrm{n}=482)$ stated a preference for a long acting reversible Table 1: Characteristics of study participants.

\begin{tabular}{|c|c|c|c|}
\hline & & $\mathbf{N}$ & $\%$ \\
\hline \multirow{5}{*}{ Highest level of education } & None & 23 & 6.8 \\
\hline & Primary school & 57 & 16.9 \\
\hline & Junior secondary school & 125 & 37.1 \\
\hline & Senior secondary school & 73 & 21.7 \\
\hline & More than secondary school & 59 & 17.5 \\
\hline \multirow{2}{*}{ Married } & Yes & 234 & 60.2 \\
\hline & No & 155 & 39.8 \\
\hline Age & Mean (s.d.) & $29.4(6.69)$ & Range: $17-51$ \\
\hline \multirow{8}{*}{ How many children } & 0 & 1 & 0.3 \\
\hline & 1 & 93 & 27.6 \\
\hline & 2 & 79 & 23.4 \\
\hline & 3 & 61 & 18.1 \\
\hline & 4 & 43 & 12.8 \\
\hline & 5 & 20 & 5.9 \\
\hline & $6+$ & 22 & 6.5 \\
\hline & Missing & 18 & 5.3 \\
\hline \multirow{2}{*}{ Ever used a method before } & Yes & 159 & 47.3 \\
\hline & No & 177 & 52.7 \\
\hline \multirow{6}{*}{ Which method } & Pill & 44 & 13.1 \\
\hline & IUD & 9 & 2.7 \\
\hline & Injectable & 83 & 24.6 \\
\hline & Implant & 24 & 7.1 \\
\hline & Male condom & 13 & 3.9 \\
\hline & Female condom & 2 & 0.6 \\
\hline \multirow{7}{*}{ Which method do you most prefer? } & Female sterilization & 12 & 3.6 \\
\hline & Pill & 16 & 4.7 \\
\hline & IUD & 45 & 13.4 \\
\hline & Injectable & 109 & 32.3 \\
\hline & Implant & 137 & 40.7 \\
\hline & Male condom & 1 & 0.3 \\
\hline & I don't know & 17 & 5 \\
\hline How strongly do you feel about this method? & Very strongly & 118 & 35 \\
\hline
\end{tabular}

contraceptive (LARC) method (either an implant (40.7\%, $\mathrm{n}=137)$ or an IUD $(13.4 \%, \mathrm{n}=45)$ ), while a sizable minority of the participants stated a preference for an injectable $(32.3 \%, \mathrm{n}=109)$. The participants in this study stated they felt either very strongly $(35.0 \%, \mathrm{n}=118)$ or strongly $(41.5 \%, \mathrm{n}=140)$ about their method preference. Only $5 \%(n=17)$ participants said they did not know which method they preferred.

While $84.5 \%(n=305)$ of the participants reported in the postvisit survey that they received the method they preferred, when their adopted method was compared to the method they reported in the pre-visit survey as their preference, $73.2 \%(n=246)$ were actually leaving with the method they indicated in the pre-visit survey as the method they most preferred. More information about the participants can be seen in Table 1 . 


\begin{tabular}{|c|c|c|c|}
\hline & Strongly & 140 & 41.5 \\
\hline & A little & 33 & 9.8 \\
\hline & I am not sure & 36 & 9.9 \\
\hline & Not at all & 8 & 2.4 \\
\hline & Missing & 2 & 0.6 \\
\hline \multirow{6}{*}{ What method are you leaving with today? } & Female sterilization & 10 & 3 \\
\hline & The pill & 27 & 8 \\
\hline & IUD & 52 & 15.4 \\
\hline & Injectable & 109 & 32.3 \\
\hline & Implant & 135 & 40.1 \\
\hline & Male condoms & 2 & 0.6 \\
\hline \multirow{3}{*}{$\begin{array}{l}\text { Did the provider you met with ask you if you knew what } \\
\text { method you wanted? }\end{array}$} & Yes & 297 & 88.1 \\
\hline & No & 7 & 2.1 \\
\hline & Missing & 33 & 9.8 \\
\hline \multirow{2}{*}{ Did you receive the method you wanted? } & Yes & 305 & 84.5 \\
\hline & No & 55 & 15.2 \\
\hline \multirow{3}{*}{ Received method initially preferred } & Yes & 246 & 73.2 \\
\hline & No & 64 & 19 \\
\hline & Missing & 27 & 8 \\
\hline \multirow{5}{*}{$\begin{array}{l}\text { How satisfied are you that you are leaving with this } \\
\text { method? }\end{array}$} & Very dissatisfied & 3 & 0.9 \\
\hline & Dissatisfied & 4 & 1.2 \\
\hline & Neutral & 13 & 3.9 \\
\hline & Satisfied & 156 & 46.3 \\
\hline & Very satisfied & 161 & 47.8 \\
\hline \multirow{2}{*}{$\begin{array}{l}\text { Did the provider tell you why they did not want you to } \\
\text { have the method you originally chose? }(\mathrm{n}=21)\end{array}$} & Yes & 15 & 71.4 \\
\hline & No & 6 & 28.6 \\
\hline
\end{tabular}

Table 2: Method preferred versus method adopted.

\begin{tabular}{|c|c|c|c|c|c|c|c|}
\hline & & \multicolumn{6}{|c|}{ Method Adopted } \\
\hline & & $\begin{array}{c}\text { Female sterilization } \\
\mathrm{N}(\%)\end{array}$ & Pill N (\%) & IUD N (\%) & $\begin{array}{c}\text { Injectable } \mathrm{N} \\
(\%)\end{array}$ & $\begin{array}{l}\text { Implant } N \\
(\%)\end{array}$ & $\begin{array}{l}\text { Male Condom } \\
\text { N (\%) }\end{array}$ \\
\hline \multirow{7}{*}{$\begin{array}{l}\text { Method Preferred before } \\
\text { counseling }\end{array}$} & Female sterilization & $9(75)$ & 1 & 1 & 0 & 1 & 0 \\
\hline & Pill & 0 & $14(93.3)$ & 0 & 1 & 0 & 0 \\
\hline & IUD & 0 & 1 & 39 (86.7) & 3 & 2 & 0 \\
\hline & Injectable & 0 & 5 & 2 & $88(80.7)$ & 14 & 0 \\
\hline & Implant & 0 & 3 & 7 & 14 & $112(81.8)$ & 1 \\
\hline & Male condom & 0 & 0 & 0 & 0 & 0 & $1(100)$ \\
\hline & I don't know & 1 & 3 & 3 & 3 & 6 & 0 \\
\hline \multicolumn{2}{|c|}{ Total } & 10 & 27 & 52 & 109 & 135 & 2 \\
\hline
\end{tabular}

Table 3: Method preferred versus method adopted.

\begin{tabular}{|c|c|c|c|c|c|}
\hline & $\begin{array}{c}\text { Very } \\
\text { dissatisfied }\end{array}$ & $\begin{array}{c}\text { Dissat- } \\
\text { isfied }\end{array}$ & Neutral & $\begin{array}{c}\text { Satis- } \\
\text { fied }\end{array}$ & $\begin{array}{c}\text { Very } \\
\text { satisfied }\end{array}$ \\
\hline $\begin{array}{c}\text { Female } \\
\text { sterilization }\end{array}$ & 0 & 0 & 0 & 6 & 4 \\
\hline Pill & 0 & 2 & 2 & 14 & 9 \\
\hline IUD & 1 & 1 & 1 & 20 & 29 \\
\hline Injectable & 1 & 1 & 5 & 52 & 50 \\
\hline Implant & 1 & 0 & 5 & 62 & 67 \\
\hline Male condom & 0 & 0 & 0 & 1 & 1 \\
\hline
\end{tabular}

For the most part, the participants in this study left with the method they indicated they preferred. For example, 112 of the 137 who said they preferred the implant left with it $(81.8 \%)$ and this does not appear to be different across methods. Preference and methods adopted did not differ by clinic location (data not shown). Participants were almost uniformly satisfied or very satisfied with the method they were leaving with, and this did not differ across methods.

In bivariate logistic regression analysis, older and married women and those with higher education were more likely to 


\section{Global Journal of Reproductive Medicine}

want the IUD, while unmarried and younger women preferred the injection. Women who wanted a method that would protect them for multiple years showed preference for the IUD and the implant, while women who wanted pregnancy protection for a few months and those who did not want a method which requires a visit to the clinic to stop using preferred the injection. Being married, being more educated, and preferring the IUD were all positively associated with adopting the IUD and being younger and preferring the injection were associated with adopting the injection. Preferring the method was the most associated factor with adopting that method (with odds ratios ranging from 43.7 for the implant to 171.6 for the IUD). Full results of the regression analyses can be seen in Table 4 .

Table 4: Bivariate logistic regression.

\begin{tabular}{|c|c|c|c|c|c|c|}
\hline \multicolumn{7}{|c|}{ Unadjusted Odds Ratio ( $95 \% \mathrm{CI}$ ) } \\
\hline & IUD Preference & Implant Preference & Injection Preference & IUD adoption & Implant Adoption & Injection Adoption \\
\hline Higher education & $2.07(1.50-2.87)^{*}$ & $.683(.555-.839)^{* * *}$ & $1.02(.831-1.25)$ & $1.80(1.35-2.41)^{*}$ & $.745(.611-.907)^{* *}$ & $1.00(.822-1.30)$ \\
\hline Married & $4.36(1.88-10.1)^{*}$ & $1.24(.787-1.94)$ & $.449(.280-.720)^{*}$ & $3.59(1.68-7.65)^{*}$ & $1.56(.996-2.42)$ & $1.55(.978-2.47)$ \\
\hline $\begin{array}{c}\text { Wanting a method } \\
\text { that lasts for } \\
\text { months }\end{array}$ & $\begin{array}{l}.480(.352- \\
.655)^{* * *}\end{array}$ & $.501(.419-.597)^{* * *}$ & $4.65(3.42-6.31)^{*}$ & $\begin{array}{l}.559(.434- \\
.721)^{* * *}\end{array}$ & $.546(.461-.646)^{* * *}$ & $\begin{array}{l}3.34(2.63- \\
4.24)^{* * *}\end{array}$ \\
\hline $\begin{array}{l}\text { Wanting a method } \\
\text { that last for years }\end{array}$ & $1.56(1.16-2.09)^{* *}$ & $2.10(1.69-2.63)^{* * *}$ & $.450(.373-.543)^{* * *}$ & $1.55(1.17-2.05)^{* *}$ & $1.73(1.43-2.10)^{* * *}$ & $\begin{array}{l}.510(.428- \\
.607)^{* * *}\end{array}$ \\
\hline $\begin{array}{l}\text { Having more } \\
\text { children }\end{array}$ & $1.05(.862-1.28)$ & $1.04(.905-1.20)$ & $.810(.688-.954)^{*}$ & $1.06(.884-1.28)$ & $1.03(.897-1.19)$ & $.783(.662-.925)^{* *}$ \\
\hline $\begin{array}{c}\text { Preferring a } \\
\text { method which } \\
\text { does not require a } \\
\text { clinic visit to stop }\end{array}$ & $.858(.697-1.06)$ & $.553(.467-.654)^{* * *}$ & $1.73(1.48-2.03)^{*}$ & $.900(.743-1.09)$ & $.570(.483-.673)^{* * *}$ & $\begin{array}{c}1.60(1.38- \\
1.87)^{* * *}\end{array}$ \\
\hline \multirow[t]{2}{*}{ Age } & $1.07(1.02-1.12)^{*}$ & $.977(.945-1.01)$ & $.954(.920-.989)^{*}$ & $1.06(1.01-1.11)^{* *}$ & $.975(.943-1.01)$ & $.955(.921-.989)^{*}$ \\
\hline & --.- & ----- & ----- & $\begin{array}{c}171.6(59.1- \\
498.5)^{*}\end{array}$ & - & ---- \\
\hline $\begin{array}{l}\text { Injection } \\
\text { preference }\end{array}$ & ---. & - & $---\cdot$ & ------------ & 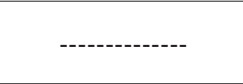 & $44.9(22.8-88.5)^{*}$ \\
\hline Implant preference & ------------ & -------------- & ------------- & 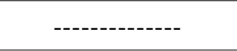 & $43.7(22.6-84.7)^{* * *}$ & ------------ \\
\hline
\end{tabular}

Legend: ${ }^{*} p<.05 ;{ }^{* *} p<.01 ;{ }^{* *} p<.001$

\section{Discussion}

In this study of 337 contraception adopters from five hospitalbased family planning clinics in two cities in Ghana, women had strong preferences about what method of contraception they wanted, and most women left with the method they indicated they preferred. The implant was the most preferred method, and the most highly adopted method, with $40.7 \%$ of women stating this was their preference and $40.1 \%$ leaving with that method. This finding is highly different from other studies, both in Ghana and in other sub-Saharan African countries. For example, in the 2014 Ghana DHS, $18.2 \%$ of women were currently using a modern method of contraception, and the implant was used by $3.7 \%$ of women, while the injection was used by $6.0 \%$ of them (GSS 2014). Even in the Greater Accra region, where $19.4 \%$ of women use a modern method of contraception, 5.9\% use an implant, and $4.8 \%$ use the injection. In a 2012 community-based study, injections were the most highly used form of hormonal contraception (and second only behind condoms) and implants were not included in the analysis [10].

In an analysis of 95 surveys in 38 sub-Saharan African countries, Ross and Agwanda [11] showed that injections were used predominately in east and southern Africa, while in the west and central parts of the continent, condoms and traditional methods were the most common methods. Our findings diverge from those. Our finding is, however, similar to a facility-based study in Kenya where 97 of 396 women (24.5\%) adopted the implant [12], suggesting differences may be due to the different data collection method (facility versus community-based). While the method mix across sub-Saharan Africa is still dominated by injections, a recent study found that between 2008 and 2014 IUD uptake increased by $429 \%$ and Implant uptake increased by $1567 \%$ at Marie Stopes International facilities and outreach programs [13], perhaps signaling a change in women's preferences away from short-term hormonal methods to LARC methods. Our findings support this observation, where over half of the participants came to their family planning counseling sessions wanting a LARC method.

Women's preferences were not equally distributed across the participants. Women who were married and had higher levels of education were more likely to prefer the IUD, while women who were unmarried were more likely to want the injection. Preferences were also not equally distributed among method characteristics; women who wanted a method that lasted for a few years were more likely to state a preference for the IUD and the implant, while women who did not want to have to go to a clinic to stop their method were more likely to prefer the injection. Older and more educated women preferring the IUD is supported by data from across sub-Saharan Africa. 


\section{Global Journal of Reproductive Medicine}

Preference was also highly related to method adoption. Women who preferred the IUD were highly more likely to adopt the IUD, women who preferred the implant were more likely to adopt the implant, and women who preferred the injection were highly more likely to adopt the injection, perhaps signaling relatively high levels of quality on that metric. Women indicated almost universal satisfaction with that they were leaving with the method they adopted, although this could be due to social desirability bias given that the data were collected in the family planning clinic. We tried to reduce this bias by having the survey filled in a private room, and the research assistants were not related to the participants' care team. However, it is likely that some women were reluctant to criticize the care they received when in such close proximity to it.

In this study, we did not observe the patient-provider interactions, so we cannot assess the quality of the counseling women received. While most women who wanted a particular method left with that method, it would be interesting to know why those who changed from the method they stated preferring in the pre-session survey to the method they adopted. The generalizability of this study is limited by how the data were collected; in family planning clinics associated with teaching and district hospitals. The women who patronize these settings are likely different from women who access contraception from other locations, and urban women are more likely than their rural counterparts to adopt LARC methods, in Ghana and elsewhere.

Although there has been much progress in recent decades tailoring family planning programming to meet women's preferences, these programs are still often framed in population control and economic growth lenses. While these may be important off-shoots of successful family planning programs, keeping the emphasis on allowing women to access high quality programs that meet their needs is of the upmost importance. This study shows that Ghanaian women have strong opinions about the method of contraception they want. If providers and health planners ignore these opinions and preferences, women will not patronize family planning clinics and the goals of the family planning community will not be met.

Ethics approval and consent to participate: All study procedures and documents were reviewed and approved by the Ghana Health Service Ethical Review Committee, and the University of Michigan Institutional Review Board. All participants completed a comprehensive informed consent procedure.

\section{Consent for Publication}

All participants were made aware during the informed consent procedure that their data may be used for scientific publication, without reporting any identifying information. Availability of data and materials: The datasets used and/or analysed during the current study are available from the corresponding author on reasonable request.

\section{Competing Interests}

VK is a paid consultant for Bayer.

\section{Funding}

This study was funded by a grant from the Institute for Research on Women and Gender, University of Michigan.

\section{Authors' Contributions}

All authors conceived the study. AM, ESKM, and EM oversaw data collection. SDR managed and analyzed the data, and wrote the first draft of the paper. All authors reviewed and revised the manuscript.

\section{References}

1. RamaRoa S, Jain A (2015) Aligning goals, intents, and performance indicators in family planning service delivery. Studies in Family Planning 46(1): 97-104.

2. Bruce J (1990) Fundamental elements of the quality of care: a simple framework. Stud Fam Plann 21(2): 61-91.

3. Bertrand JT, Sullivan TM, Knowles EA, Zeeshan MF, Shelton JD (2014) Contraceptive method skew and shift in method mix in low- and middle-income countries. Int Perspect Sex Reprod Health 10(3): 144153.

4. Sullivan TM, Bertrand JT, Rice J, Shelton JD (2006) Skewed contraceptive method mix: why it happens, why it matters. J Biosoc Sci 38(4): 501521.

5. FP2020 (2014) Partnership in progress: annual progress report. FP2020, Washington DC, USA

6. Ghana Statistical Service (GSS), Ghana Health Service (GHS), ICF Macro (2009) Ghana Demographic and Health Survey 2008. Accra, Ghana: GSS, GHS, and ICF Macro Pp.79-87.

7. Ghana Statistical Service (GSS), Ghana Health Service (GHS), ICF Macro (2015) Ghana Demographic and Health Survey 2014. Accra, Ghana: GSS, GHS, and ICF Macro, Pp. 83.

8. Machiyama K, Cleland J (2014) Unmet need for family planning in Ghana: The shifting contributions of lack of access and attitudinal resistance. Stud Fam Plann 45(2): 203-226.

9. Pariani S, Heer DM, Van Arsdol (1991) Does choice make a difference to contraceptive use? Evidence from East Java. Stud Fam Plann 22(6): 384-390.

10. Adanu RM, Seffah J, Anarfi JK, Lince N, Blanchard K (2012) Sexual and Reproductive Health in Accra, Ghana. Ghana Med J 46(2): 58-65.

11. Ross JA, Agwanda AT (2012) Increased Use of Injectable Contraception in Sub-Saharan Africa. Afr J Reprod Health 16(14): 68-80.

12. O'Neill E, Tang J, Garrett J, Hubacher D (2014) Characteristics of Kenyan women in a prospective cohort study who continue using subdermal contraceptive implants at 12 months. Contraception 89(3): 204-208.

13. Ngo TD, Nuccio O, Pereira SK, Footman K, Reiss K (2017) Evaluating a LARC expansion program in 14 sub-Saharan Africa countries: A service delivery model for meeting FP2020 goal. Matern Child Health J 21(19): 1734-1743. 
(CC) Tommons Attribution 4.0 License

(C) $\begin{array}{ll}\text { CY } & \text { Commons Attribution 4.0 License } \\ \text { DOI: } 10.19080 / \text { GJORM.2018.06.555677 }\end{array}$

Your next submission with Juniper Publishers
will reach you the below assets
- Quality Editorial service
- Swift Peer Review
- Reprints availability
- E-prints Service
- Manuscript Podcast for convenient understanding
- Global attainment for your research
- Manuscript accessibility in different formats
( Pdf, E-pub, Full Text, Audio)
- Unceasing customer service
Track the below URL for one-step submission
https://juniperpublishers.com/online-submission.php

